\title{
Influence of Air Temperature on the Drying Kinetics and Quality of Tomato Slices
}

\author{
Abano E. $E^{1,3 *}$, Ma. $H^{1,2}$ and W. $Q u^{1}$
}

${ }^{1}$ School of Food and Biological Engineering, Jiangsu University, 301 Xuefu Road, Zhenjiang 212013, China

2Jiangsu Provincial Research Center of Bio-process and Separation Engineering of Agri-products, Jiangsu University, 301 Xuefu Road, Zhenjiang 212013, China

${ }^{3}$ Agricultural Engineering Department, University of Cape Coast, Cape Coast, Ghana

\begin{abstract}
The influence of different drying temperatures on the drying kinetics and quality of tomato slices was studied. In particular, the effect of hot air temperature on the lycopene content, non-enzymatic browning, colour and flavour changes during drying at various temperatures in the range of $50-80^{\circ} \mathrm{C}$ was investigated. Drying time reduced from 1140 mins to 540 mins as the air temperature increased from 50 to $80^{\circ} \mathrm{C}$. The non-enzymatic browning increased with temperature from 0.485 to 1.40 . The lycopene levels of the fresh tomatoes significantly $(p=0.05)$ increased from an initial value of $2.96 \mathrm{mg} / 100 \mathrm{~g}$ to $61.23 \mathrm{mg} / 100 \mathrm{~g}, 59.10 \mathrm{mg} / 100 \mathrm{~g}, 60.88 \mathrm{mg} / 100 \mathrm{~g}$, and $65.28 \mathrm{mg} / 100 \mathrm{~g}$ when dried at $50,60,70$, and $80^{\circ} \mathrm{C}$ respectively. Eleven out of the twelve sensors used in the electronic nose system indicated flavour degradation of all dried samples compared with the fresh tomatoes. The values of the hue angles recorded for the dried tomatoes ranged between $51.81^{\circ}$ and $61.95^{\circ}$, revealing that the dried tomatoes were yellow hued, thus indicating less browning. The drying characteristics curves were evaluated against the Page, Henderson and Pabis, and the Logarithmic mathematical models but the Page model best described the drying of tomato slices. The effective moisture diffusivity coefficient increased with increasing drying temperature and was found to be $5.13 \times 10^{-10}$ $\mathrm{m}^{2} \mathrm{~s}^{-1}, 6.45 \times 10^{-10} \mathrm{~m}^{2} \mathrm{~s}^{-1}, 8.44 \times 10^{-10} \mathrm{~m}^{2} \mathrm{~s}^{-1}$, and $10.26 \times 10^{-10} \mathrm{~m}^{2} \mathrm{~s}^{-1}$ at respective hot air temperatures of $50,60,70$, and $80^{\circ} \mathrm{C}$ with activation energy for moisture removal of $22.28 \mathrm{KJ} / \mathrm{mol}$.
\end{abstract}

Keywords: Tomato slices; Drying characteristics; Lycopene; Nonenzymatic browning; Colour; flavour

\section{Introduction}

Tomato (Lycopersicon esculentum) cultivation is wide spread throughout the world [1]. The tomato crop is noted to be the second most important vegetable crop next to potato [2]. Globally, China is by far the largest producer of tomatoes, followed by the USA, India, Egypt and Turkey [3]. Many developing countries still face enormous challenges of postharvest losses of tomatoes due to inadequate processing and storage facilities. Tomatoes produced in the peak seasons are either consumed fresh, sold at relatively cheap prices, or are allowed to go waste [4]. Studies show that tomato contains a large amount of lycopene, which is the major carotenoid, accounting for $90 \%$ of the total carotenoids [5]. Lycopene's antioxidant activity is reported to be higher than $\beta$-carotene, $\gamma$-carotene, and $\alpha$-tocopherol, which provides effective scavenging effects on cancer causing free radicals. Epidemiological studies have shown that lycopene in tomato is particularly effective in fighting prostate cancer, cervical cancer, cancer of the stomach and rectum as well as pharynx and oesophageal cancers [6]. Studies done by Toğrul [7] indicated that among the caroteniods, lycopene is the compound that produces the greatest number of unsaturations, having a total of 13 double bonds, with 11 of them conjugated in structure. The conjugated double bond in lycopene is responsible for the red colour of ripe tomato and its antioxidant activity $[8,9]$. Other medicinal benefits of tomatoes include reduction of cholesterol, improvement of vision, maintenance of gut, lowering of hypertension, alleviation of diabetes, protection of the skin, prevention of urinary tract infections and gallstones. Lycopene is used in cosmetics and pharmaceutical products and is an excellent natural colourant in several food formulations $[8,10]$. Other authors have suggested that lycopene in tomato can chelate singlet oxygen [9] with a chelating constant two times higher than that of $\beta$-carotene [11]. Additionally, lycopene can sequester nitrogen dioxide $\left(\mathrm{NO}_{2}\right)$ and sulfide (RS) free radicals and inhibit DNA and cellular membrane damage due to its oxidative processes. Several reports show high correlation of carotenoid consumption and reduction of diseases such as cancer, artherogenesis, bone calcification deficiencies, macular degeneration, neuron damage, and heart problems [12-16].

The most widely used commercial drying plants for numerous industrial agrifood by products are the conventional hot-air dryers, in which heat is transferred to the product by means of heated air [1]. The basic objective in dying food products is the removal of water from the solid material to certain moisture content where microbial spoilage is avoided. Longer shelf life and significant reduction in the volume of the products are major reasons for the popularity of dried food material. The objectives of energy efficient process and the highest possible product quality are conflicting in many cases in that most energy-saving measures are harmful for quality aspects and vice versa [17]. Thermal damage incurred by a product during drying is directly proportional to the temperature and time involved [18]. Even though hot-air drying is the most common method to preserve foods, many researchers believe that hot-air drying leads to degradation of products flavor, colour, nutrients, and case hardening, due to their long drying times and high temperatures employed in practice [18-20]

*Corresponding author: Abano E. E, School of Food and Biological Engineering Jiangsu University, 301 Xuefu Road, Zhenjiang 212013, China, Tel: +86 511 88790958; E-mail: mhl@ujs.edu.cn

Received September 15, 2011; Accepted November 02, 2011; Published November 20, 2011

Citation: Abano EE, Ma H, Qu W (2011) Influence of Air Temperature on the Drying Kinetics and Quality of Tomato Slices. J Food Process Technol 2:123. doi:10.4172/2157-7110.1000123

Copyright: (C) 2011 Abano EE, et al. This is an open-access article distributed under the terms of the Creative Commons Attribution License, which permits unrestricted use, distribution, and reproduction in any medium, provided the original author and source are credited. 
A Review by Vadivambal and Jayas [18] indicated that quality assessment includes three principal indicators of nutritional value, acceptability, and safety. Good quality is judged by freshness, expected appearance, flavour, and texture. Food safety is protecting the food from physical (drying out, infestation), chemical (rancidity, browning) and microbial hazards or contamination that may occur during all stages of food production, growing, harvesting, processing, transporting, distributing, and storage. In tomato drying, the colour and flavour are considered the most important quality attributes affecting the degree of acceptability of the products by consumers [17]. Research shows that, among many factors affecting the quality attributes during drying, the most important are the moisture content and temperature. Cernîşev [17] reported that the decrease in moisture content and the higher temperature of the material during drying lead to several irreversible chemical reactions as well as structural, physical and mechanical changes. In today's advanced food processing technologies, the trend is to minimize chemical degradation reactions, maximize nutrient retention, minimize energy consumption and reduce carbon footprint to produce better quality products [17].

The objective of this research was to investigate the influence of hot-air on the drying kinetics and quality attributes of tomato slices. Specifically, this research investigated the influence of the hot-air on the drying kinetics, the moisture diffusivity, and activation energy for moisture removal of tomato slices. Additionally, the study evaluated the drying characteristics of tomato slices against the Page, Henderson and Pabis, and Logarithmic drying models available in literature. In this case, the experimental dimensionless moisture ratio was fitted to the three models and to establish the influence of hot-air on the moisture diffusivity coefficient and activation energy for hot-air drying of tomato slices. Finally, the most important quality attributes of dried tomatoes such as lycopene content, flavor, colour, and non-enzymatic browning were investigated.

\section{Materials and Methods}

\section{Materials}

Fresh tomatoes of good quality from the same cultivar were procured from the Zhenjiang local Market, China. Selection was based on visual assessment of uniform colour and geometry. The initial moisture content of the tomatoes was determined at $105^{\circ} \mathrm{C}$ for 24 h. The tomato samples were washed and stored in a refrigerator at a temperature $4^{\circ} \mathrm{C}$ in order to slow down the physiological and chemical changes [21,22]. Prior to drying, the individual tomatoes were cut into slices of thickness $7 \mathrm{~mm}$ using a cutting machine (SS-250, SEP Machinery Company Ltd, Guangzhou, China).

\section{Drying equipment and drying method}

The adjustable cabinet hot-air dryer used in the study (Shanghai Experimental Apparatus Company Limited, 101C-3B) has the technical features of $230 / 380 \mathrm{~V} 50 \mathrm{~Hz}$ and $59 \mathrm{~kW}$, with a maximum temperature of $300^{\circ} \mathrm{C}$ (Figure 1). 100g of the tomato slices were dried at drying air temperatures of $50,60,70$, and $80^{\circ} \mathrm{C}$ with three replications. The masses of the drying samples were monitored every $30 \mathrm{~min}$ at the initial stages and later changed to $1 \mathrm{~h}$ at the later stages of drying until constant mass was observed. The electronic balance used to monitor the mass of drying samples was of $0.01 \mathrm{~g}$ precision (Sartorius BS2202S, Germany). The tomato slices were put in a thin layer on a round stainless steel meshed bowl and dried to a final moisture content of about $0.18 \mathrm{~kg}$ water per kg dry matter. The average moisture content was used to plot the drying characteristics curves for the temperature range studied with dimensionless moisture ratio against drying time.

\section{Drying kinetics expressed in terms of empirical models}

The drying kinetics of tomato slices was expressed in terms of empirical models, where the experimental data obtained for the four different temperatures $\left(50,60,70\right.$ and $\left.80^{\circ} \mathrm{C}\right)$ were plotted in the form of dimensionless moisture ratio (MR)[Equation 1] against drying time (expressed in $\mathrm{min}$ ).

$$
M R=\frac{\mathrm{M}-\mathrm{M}_{\mathrm{e}}}{\mathrm{M}_{0}-\mathrm{M}_{\mathrm{e}}}
$$

Where, $\mathrm{MR}$ is the moisture ratio, $\mathrm{M}$ is the moisture content at any time, $t, M_{e}$ is the equilibrium moisture content, and $M_{0}$ is the initial moisture content.

The drying rate of tomato slices was calculated using [Equation 2] [23], where $\mathrm{M}_{\mathrm{t}+\mathrm{dt}}$ is the moisture content (kg water per kg dry matter) at $\mathrm{t}+\mathrm{dt}$, and $\mathrm{t}$ is the drying time $(\mathrm{min})$

$$
D R=\frac{\mathrm{M}_{\mathrm{t}+\mathrm{dt}}-\mathrm{M}_{\mathrm{t}}}{\mathrm{dt}}
$$

The experimental set of $(M R, t)$ were fitted to three different empirical drying models widely used in scientific literature shown in Table 1 to describe the drying kinetics of tomato slices. Three primary criteria were used to determine the goodness of fit to the models; the correlation coefficient $\left(\mathrm{R}^{2}\right)$, the root mean square error (RMSE) and the reduced chi-square $\left(\chi^{2}\right)$. The highest $\mathrm{R}^{2}$, lowest $\chi^{2}$ and RMSE were used to determine the goodness of fit. Several authors have used these criteria to select the best models for drying mistletoe [24], onion slices [25], aromatic plants [26], olive leaves [27], okra [28], thyme [23], and aloe vera [29].

The different statistical evaluation [Equations 3, 4, and 5] to describe the goodness of fit of the dried tomato slices are as follows:

$$
R^{2}=\frac{N \sum_{i=1}^{N} M R_{\text {pred }, i} M R_{\text {expt }, i}-\sum_{i=1}^{N} M R_{\text {pred }, i} \sum_{i=1}^{N} M R_{\text {expt } x, i}}{\sqrt{\left(N \sum_{i=1}^{N} M R_{\text {pred }, i}^{2}-\left(\sum_{i=1}^{N} M R_{\text {pred }, i}\right)^{2}\right)\left(N \sum_{i=1}^{N} M R_{\text {expt }, i}^{2}-\left(\sum_{i=1}^{N} M R_{\text {expt }, i}\right)^{2}\right)}}
$$

\begin{tabular}{|l|l|l|}
\hline Model name & Model Expression & References \\
\hline Page & $M R=\exp \left(-k t^{n}\right)$ & Page (1949) \\
\hline Logarithmic & $M R=a \exp (-k t)+c$ & Doymaz.(2010) \\
\hline Henderson \& Pabis & $M R=a \exp (-k t)$ & Ghodake et al.(2006) \\
\hline
\end{tabular}

Table 1: Mathematical models that was applied to the drying curves.

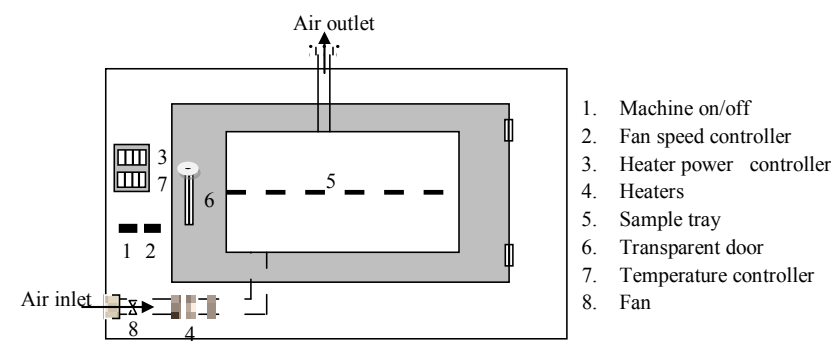

Figure 1: Schematic diagram of the dryer used in the experiment 


$$
\begin{aligned}
& R M S E=\sqrt{\frac{1}{N} \sum_{i=1}^{N}\left(M R_{\text {expt }, i}-M R_{\text {pred }, i}\right)^{2}} \\
& \chi^{2}=\frac{\sum_{i=1}^{N}\left(M R_{\text {expt }, i}-M R_{\text {pred }, i}\right)^{2}}{N-z}
\end{aligned}
$$

Where $\mathrm{MR}_{\text {expt'i }}$ and $\mathrm{MR}_{\text {pred,i }}$ are the experimental and predicted dimensionless MR respectively, $\mathrm{N}$ is the number of observations, and $\mathrm{z}$ is the number of model constants. The drying rate constants and coefficients of the model equations were determined with nonlinear regression of SPSS 16.0 [30], and the goodness of fit of the curves was determined with correlation analysis.

\section{Calculation of moisture diffusivity and Activation Energy}

Fick's second law of diffusion [Equation 6] has been widely used to describe the drying process during the falling rate period for agricultural materials $[23,31,32]$

$$
\frac{\partial M}{\partial t}=\mathrm{D}_{\mathrm{eff}} \nabla^{2} M
$$

[Equation 6] is solved by Crank [34] for an infinite slab, assuming undimensional moisture movement volume change, constant temperature and diffusivity coefficient, and negligible external resistance. The solution is of the form:

$$
M R=\frac{M-M_{e}}{M_{0}-M_{e}}=\frac{8}{\pi^{2}} \sum_{n=0}^{\infty} \frac{1}{(2 n+1)^{2}} \exp \left[\frac{-(2 n+1)^{2} \pi^{2} D_{e f f} t}{4 L^{2}}\right]
$$

For long drying times, [Equation 7] simplifies to a limiting form of the diffusion equation as given by [Equation 8]

$$
M R=\frac{M-M_{e}}{M_{0}-M_{e}}=\frac{8}{\pi^{2}} \exp \left(\frac{-\pi^{2} D_{e f f} t}{4 L^{2}}\right)
$$

From [Equation 8], $\mathrm{D}_{\text {eff }}$ of the tomato slices was obtained from the slope $(\mathrm{K})$ of the graph of InMR against the drying time. InMR versus time results in a straight line with negative slope and $\mathrm{K}$ is related to $\mathrm{D}_{\text {eff }}$ by [Equation 9].

$$
K=\frac{\pi^{2} D_{e f f}}{4 L^{2}}
$$

Where, MR is the moisture ratio, $\mathrm{D}_{\text {eff }}$ is the effective moisture diffusivity $\left(\mathrm{m}^{2} / \mathrm{s}\right)$, and $\mathrm{L}$ is half the thickness of slice of the sample $(\mathrm{m})$, $\mathrm{M}$ is the moisture content at any time, $\mathrm{t}, \mathrm{M}_{\mathrm{e}}$ is the equilibrium moisture content, and $\mathrm{M}_{0}$ is the initial moisture content. [23]

$\mathrm{D}_{\text {eff }}$ can be related to the temperature by Arrhenius [Equation 10]

$$
D_{e f f}=D_{0} \exp \left(-\frac{E_{a}}{R(T+273.15)}\right)
$$

Where $\mathrm{D}_{\mathrm{o}}$ is the constant in the Arrhenius equation $\left(\mathrm{m}^{2} / \mathrm{s}\right), \mathrm{E}_{\mathrm{a}}$ is the activation energy $(\mathrm{KJ} / \mathrm{mol})$, $\mathrm{T}$ is the temperature of hot-air $\left({ }^{\circ} \mathrm{C}\right)$, and $\mathrm{R}$ is the universal gas constant $\left(8.31451 \mathrm{kJmol}^{-1} \mathrm{~K}^{-1}\right)$. [Equation 11] can be rearranged into the form:

$$
\operatorname{In}\left(D_{\text {eff }}\right)=\operatorname{In}\left(D_{0}\right)-\frac{\mathrm{E}_{\mathrm{a}}}{R(T+273.15)}
$$

The activation energy for moisture diffusion was obtained from the slope of the graph of In $\left(D_{\text {eff }}\right)$ against $1 / T+273.15$

\section{Colour measurements}

The colour of the fresh and dried tomato slices was measured in Hunter parameters with an automatic colour difference meter (DC-P3, Beijing, China). The calibration was standardized by placing the tip of the measuring heat flux against the surface of the white and black calibration plates. After standardization, three random readings were recorded; the colour brightness coordinates, $\mathrm{L}$, measures the whiteness value of a color and ranges from black at 0 to white at 100 . The Chromaticity coordinates, a, measures the red when positive and green when negative, and the chromaticity coordinate, $b$, measures yellow when positive and blue when negative. Also, the chroma, C, [Equation 12] and hue angle [Equation 13] were calculated from the values of $L$, $a$, and $b$, and used to describe the changes in color after drying. The chroma indicates colour saturation and is proportional to its intensity. The hue angle is another parameter used to characterize colour of food products. An angle of $0^{\circ}$ or $360^{\circ}$ represents red hue, while angles of $90^{\circ}$, $180^{\circ}$, and $270^{\circ}$ represent yellow, green, and blue hues respectively [22].

$$
\begin{aligned}
& C=\sqrt{a^{2}+b^{2}} \\
& \alpha=\tan ^{-1}\left(\frac{b}{a}\right)
\end{aligned}
$$

\section{Flavour measurement}

The electronic nose system for agricultural products consisting of twelve Tin dioxides semiconductor sensors array was used to monitor the flavour of the fresh and dried samples. The instrument was previously described by [34]. Four (4) grams of the fresh and reconstituted dried samples were sealed in the concentration chamber and incubated at a temperature of $20 \pm 0.8^{\circ} \mathrm{C}$ [35]. Thereafter the samples were allowed to enable the volatilization of the flavour components into the headspace and pumped into the sensor chamber at a constant flow rate of $150 \mathrm{~mL} /$ min. The sensor response pattern signals was measured using pattern recognition algorithms controlled by a commercial acquisition board computer program PCL-816 (Advantech Inc, Taiwan, China). The sensor patterns were monitored until stable values were recorded by all the twelve sensors. Measurements were recorded in resistance changes experienced by the sensors when exposed to the flavour compounds.

\section{Non-enzymatic browning determination}

A modified method of Cernîşev [17] was used to determine the browning index (BI) of the dried tomatoes. The extent of browning was evaluated as browning index measured as absorbance at $440 \mathrm{~nm}$. Brown pigments were extracted from $2 \mathrm{~g}$ test portions from the dried tomato samples. Samples were ground into fine powder with a kitchen blender for $2 \mathrm{~min}$ after which $50 \mathrm{ml}$ of ethanol $(60 \%$, v/v) was added and allowed to stand for $12 \mathrm{~h}$. After $12 \mathrm{~h}$, the mixture was agitated and then filtered through $0.45 \mu \mathrm{m}$ nylon filter membrane. Browning index of filtrates was evaluated with spectrophotometer (UNICO 7200, Shanghai, China) against $60 \%$ ethanol. All samples were extracted in duplicate.

\section{Lycopene content determination}

The lycopene in the fresh and dried tomato samples was extracted 
in acetone and then taken up in petroleum ether following the protocol. Five (5) gram of fresh tomato pulp and $1 \mathrm{~g}$ of dried tomatoes were extracted repeatedly with acetone using pestle and mortar until the residue was colourless. The acetone extract was transferred into a separating funnel containing $20 \mathrm{ml}$ petroleum ether and mixed gently. $20 \mathrm{ml}$ of $5 \%$ sodium sulphate solution was added and the separating funnel shaken gently. Another $20 \mathrm{ml}$ of petroleum ether was added to make up for any evaporated petroleum ether. The coloured pigment noticed in the upper petroleum ether was separated and the lower phase re-extracted with additional petroleum ether until colourless. The petroleum ether was washed with a little distilled water and poured into a brown bottle containing $10 \mathrm{~g}$ of anhydrous sodium sulphate and kept for at least $30 \mathrm{~min}$. The petroleum ether was decanted into a $100 \mathrm{ml}$ volumetric flask through a cotton wool in a funnel. The sodium sulphate slurry was washed with petroleum ether until it was colourless and transferred into the volumetric flask. It was topped up to the mark with petroleum ether and the absorbance measured in a spectrophotometer at $503 \mathrm{~nm}$ with petroleum ether as blank. The lycopene content $(\mathrm{mg} / 100$ g sample) was calculated using [Equation 14]

$$
L_{c}=\frac{31.206 \times \mathrm{Abs}}{\mathrm{w}_{\mathrm{t}}}
$$

Where $\mathrm{L}_{\mathrm{c}}$ is the lycopene content $(\mathrm{mg} / 100 \mathrm{~g})$, Abs is the absorbance, and $\mathrm{w}_{\mathrm{t}}$ is the weight of the sample $(\mathrm{g})$

\section{Statistical analysis}

Analysis of variance (ANOVA) was carried out with SPSS 16.0 [30] to determine the influence of hot-air on the parameters measured. The Fishers least significance difference (LSD) was used to compare differences in parameters. Where significant differences exist, the Duncan Multiple range test was employed to separate the means.

\section{Result and Discussion}

\section{Influence of hot-air temperature on drying kinetics of tomato slices}

Figure 2 show the variation of moisture ratio versus drying time for the various air temperatures of $50,60,70$, and $80^{\circ} \mathrm{C}$. The initial average moisture content of the tomatoes was $24.71 \mathrm{~kg}$ water/ $\mathrm{kg}$ dry matter, which reduced to $0.18 \mathrm{~kg}$ water $/ \mathrm{kg}$ dry matter after drying. The drying followed a falling rate period and the increase in temperature accelerated the drying process. As hot-air temperature increased, moisture removal also increased and ultimately resulted in the reduction in drying time. Drying time reduced from 1140 mins to 540 mins as the air temperature increased from 50 to $80^{\circ} \mathrm{C}$. This means that there was significant savings in time as hot-air temperature increased. The results agree with what reported by Contreras et al. [20], BaiNgew et al. [36], Figel [37], Karaaslan and Tuncer [22] for microwave drying of apple and strawberry, durian chips, beetroot, and spinach respectively.

The drying rates (DR) obtained in unit time for the different temperatures are given in Figure 3. DR increased with the increase of air temperature, with the highest values of DR obtained during the experiment at $80^{\circ} \mathrm{C}$. From the curves, it is clearly shown that the drying temperature had a significant effect on the DR. It was found that during the drying process of tomato slices at air temperatures of 50 and $60^{\circ} \mathrm{C}$, there was a constant rate drying period when the moisture decrease from 25 to $15 \mathrm{~kg}$ water $/ \mathrm{kg}$ dry matter. On the contrary, no similar trend was observed for the 70 and $80^{\circ} \mathrm{C}$ dried samples. This indicates that

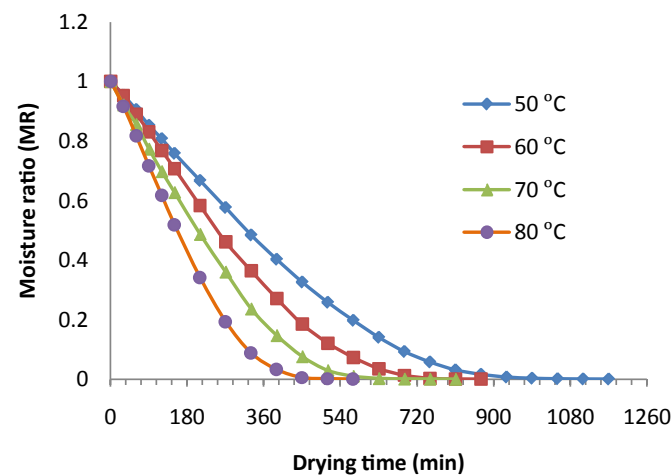

Figure 2: Variation of moisture ratio against drying time at various hot-air temperatures.

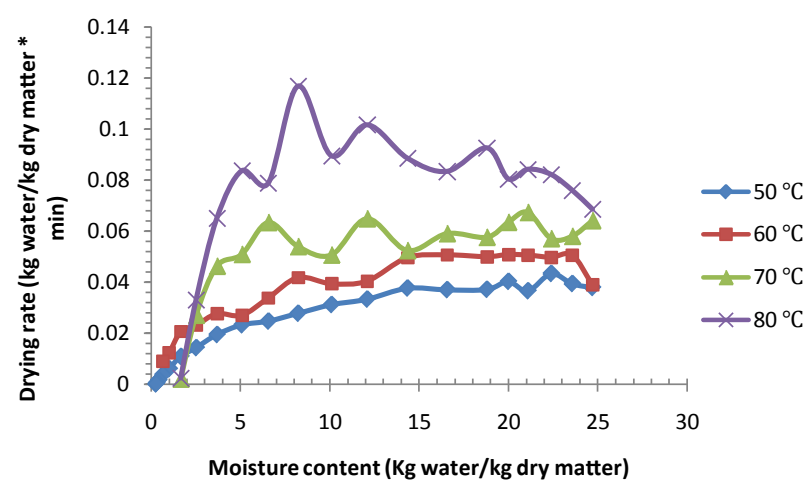

Figure 3: Variation of drying rate against moisture content at various hot-air temperatures.

diffusion is the most likely physical mechanism governing moisture movement in the tomato particles. Similar results were reported for hot-air drying of thyme [23], onion slices, and Rehmannia.

\section{Moisture diffusivity and activation energy}

The variation of In (MR) against drying time for the tomato slices dried at $50,60,70$, and $80^{\circ} \mathrm{C}$ is shown in Figure 4. In general, it was found that the plot of In (MR) against time followed a straight line regression equation with negative slope. However, at the latter stages of drying, the trend did not follow the straight line. The results of the effective moisture diffusivity coefficient, $\mathrm{D}_{\text {eff }}$, at the different air temperatures studied, increased with hot-air temperature with corresponding values of $5.13 \times 10^{-10} \mathrm{~m}^{2} \mathrm{~s}^{-1}, 6.45 \times 10^{-10} \mathrm{~m}^{2} \mathrm{~s}^{-1}, 8.44 \times 10^{-10} \mathrm{~m}^{2} \mathrm{~s}^{-1}$, and $10.26 \times 10^{-10}$ $\mathrm{m}^{2} \mathrm{~s}^{-1}$, at respective air temperatures of $50,60,70$, and $80^{\circ} \mathrm{C}$. The values of the $\mathrm{D}_{\text {eff }}$ obtained from this research lie within the general range of $10^{-12}-10^{-8} \mathrm{~m}^{2} \mathrm{~s}^{-1}$ for drying of food materials. The increasing trend of $\mathrm{D}_{\text {eff }}$ with increase in drying air temperature was expected because of increase in vapour pressure inside the tomato samples. The values of the correlation coefficients ranged between 0.8407 and 0.9152 . The relatively high value of correlation coefficient indicates good fitness between experimental and predicted values. The moisture diffusivity values recorded for hot-air drying of tomato slices are within those existing in literature, such as $5.30-17.73 \times 10^{-10} \mathrm{~m}^{2} \mathrm{~s}^{-1}$ for aloe vera [27], $1.345-2.658 \times 10^{-8} \mathrm{~m}^{2} \mathrm{~s}^{-1}$ for onion slices and 1.097-5.991 $\times 10^{-9} \mathrm{~m}^{2} \mathrm{~s}^{-1}$ for thyme [23]. The moisture diffusivities values were used to fit [Equation 11] to estimate the activation energy for moisture diffusion, $E_{a}$. Figure 
Citation: Abano EE, Ma H, Qu W (2011) Influence of Air Temperature on the Drying Kinetics and Quality of Tomato Slices. J Food Process Technol 2:123. doi: $10.4172 / 2157-7110.1000123$

Page 5 of 9

5 displays the Influence of hot-air temperature on effective moisture diffusivity. The results of such fitting gave a regression coefficient of 0.9977 indicating that the quality of such a fitting was good. The value obtained for the activation energy for moisture diffusion was found to be $22.28 \mathrm{KJ} / \mathrm{mol}$. The activation energy obtained in this study was relatively lower than activation energies of $26.4 \mathrm{~kJ} / \mathrm{mol}$ for drying onion slices [25], 42.80 for drying red pepper Kaymak-Ertekin [27], $47.14 \mathrm{~kJ} /$ mol for drying rehmannia, $51.26 \mathrm{~kJ} / \mathrm{mol}$ for okra drying [28], $46.86 \mathrm{~kJ} /$ mol for drying Avishan, and $73.84 \mathrm{~kJ} / \mathrm{mol}$ for thyme drying [23].

\section{Modeling of the drying curves}

The dimensionless moisture ratio against drying time for the experimental data at various air temperatures was fitted to the Page, Henderson and Pabis, and logarithmic drying models available in literature. The results of such fitting of the experimental data for the samples dried at $50^{\circ} \mathrm{C}$ are displayed in Table 2, which show the values of the estimated constants with their corresponding statistical $\mathrm{R}^{2}, \chi^{2}$, and RMSE values characterizing each fitting. From the results obtained, it is evident that the experimental data fitted to the models used in this study. The correlation coefficients obtained are in the range of 0.9771-0.9962. This means that the three models could satisfactorily describe the hot-air drying of tomato slices. The relatively high values of correlation coefficients, low reduced chi-square, and low root mean square errors indicate a good predicting capacity for the temperature tested over the entire duration of the drying process. Among the three

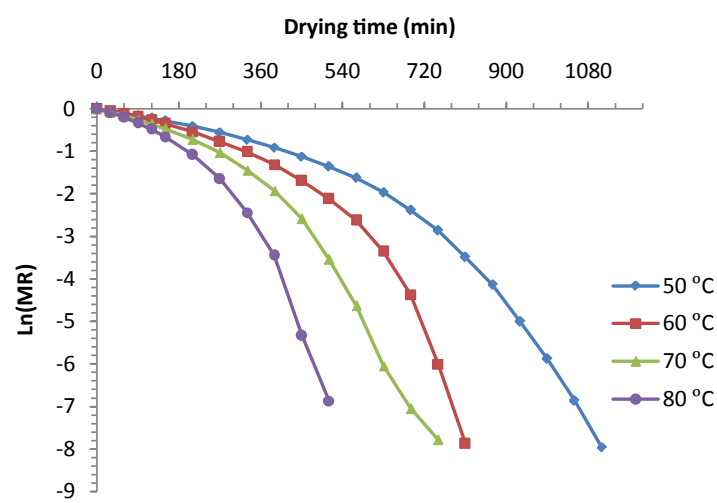

Figure 4: Variation of $\ln (\mathrm{MR})$ versus drying for the various hot-air temperatures.

$1 /(\mathrm{T}+273.15)(1 / \mathrm{K})$

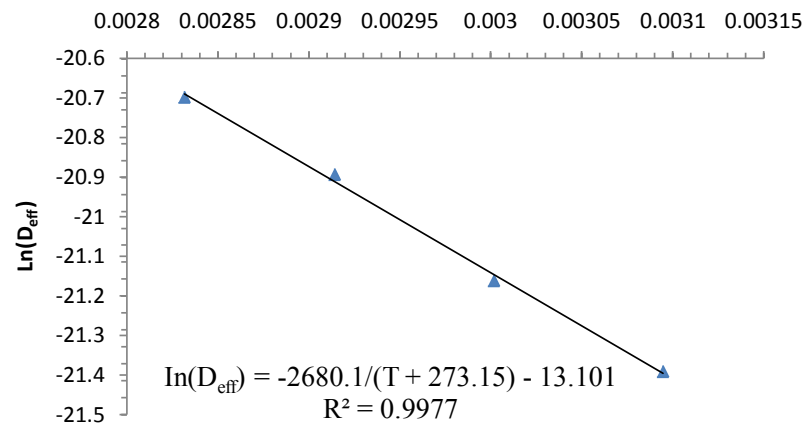

Figure 5: Influence of hot-air temperature on effective moisture diffusivity.

\begin{tabular}{|c|c|c|c|c|}
\hline Model Name & Model Constant ( \pm SEE) & $\mathrm{R}^{2}$ & RMSE & $x^{2}$ \\
\hline $50^{\circ} \mathrm{C}$ & N: 23 & & & \\
\hline Page & k: $0.00004556(0.00), n: 1.4295(0.042)$ & 0.9962 & 0.0218 & 0.00052 \\
\hline $\begin{array}{l}\text { Henderson } \\
\text { and Pabis }\end{array}$ & k: $0.003(0.00)$, a: $1.088(0.032)$ & 0.9771 & 0.0539 & 0.0031 \\
\hline Logarithmic & $\begin{array}{l}\text { k: } 0.002(0.00), \text { a: } 1.219(0.032) \\
\text { c:- } 0.173(0.036)\end{array}$ & 0.9932 & 0.0295 & 0.0010 \\
\hline $60^{\circ} \mathrm{C}$ & $\mathrm{N}: 18$ & & & \\
\hline Page & k: $0.000(0.00), n: 1.472(0.040)$ & 0.9975 & 0.0182 & 0.00037 \\
\hline $\begin{array}{l}\text { Henderson } \\
\text { and Pabis }\end{array}$ & k: 0.004(0.00), a: 1.099(0.038) & 0.9751 & 0.0572 & 0.00369 \\
\hline Logarithmic & $\begin{array}{l}\text { k: } 0.002(0.00), \text { a: } 1.263(0.044) \\
\text { c:-0.210(0.050) }\end{array}$ & 0.9932 & 0.0298 & 0.00107 \\
\hline $70^{\circ} \mathrm{C}$ & $\mathrm{N}: 17$ & & & \\
\hline Page & k: $0.000(0.00), \mathrm{n}: 1.445(0.048)$ & 0.9969 & 0.0203 & 0.00047 \\
\hline $\begin{array}{l}\text { Henderson } \\
\text { and Pabis }\end{array}$ & k: $0.004(0.00)$, a: $1.089(0.040)$ & 0.9762 & 0.05583 & 0.00353 \\
\hline Logarithmic & $\begin{array}{l}\text { k: } 0.003(0.00), \text { a: } 1.188(0.037) \\
\text { c:-0.134(0.041) }\end{array}$ & 0.9901 & 0.0360 & 0.00157 \\
\hline $80^{\circ} \mathrm{C}$ & $\mathrm{N}: 13$ & & & \\
\hline Page & k: $0.000(0.00), n: 1.505(0.047)$ & 0.9977 & 0.0175 & 0.00036 \\
\hline $\begin{array}{l}\text { Henderson } \\
\text { and Pabis }\end{array}$ & k: $0.006(0.00)$, a: $1.094(0.049)$ & 0.9720 & 0.0607 & 0.00436 \\
\hline Logarithmic & $\begin{array}{l}\text { k: } 0.004(0.001), \text { a: } 1.235(0.055) \\
\text { c:- } 0.180(0.063)\end{array}$ & 0.9895 & 0.0372 & 0.00180 \\
\hline
\end{tabular}

Table 2: Results of the fitting to experimental data for the tomato slices dried at $50,60,70$ and $80^{\circ} \mathrm{C}$.

thin-layer drying models tested, the Page model obtained the highest $\mathrm{R}^{2}$ values and the lowest $\chi^{2}$, and RMSE values. Figures 6,7 , and 8, display the fitting of the experimental and simulated points to the Page, Henderson and Pabis, and logarithmic models respectively. It can be seen from figures that the experimental data are closely bounded to the simulated data for the Page model around logarithmic curves. However, at the latter stages of drying, the experimental data were further away from the predicted data in the Henderson and Pabis and Logarithmic models.

\section{Influence of hot air on colour parameters}

The results of the colour changes in Hunter parameters obtained from the hot air drying of tomato slices at the various temperatures are displayed in Figure 9 (a, b, and c) for L(brightness), a(redness), $\mathrm{b}$ (yellowness), and Figure 10 for $\mathrm{C}\left(\right.$ Chroma), and $\mathrm{a}^{\circ}$ (hue angle) values. It is obvious that there was a significant $(p=0.05)$ increase in the brightness for all the dried tomatoes slices at the various temperatures studied in comparison with the fresh ones. However, brightness increased significantly with temperature from 60.91 to 65.47 when air temperature increased from 50 to $60^{\circ} \mathrm{C}$ and then decreased from 63.81 to 63.11 at temperatures from 70 to $80^{\circ} \mathrm{C}$. This trend shows that luminance of the fresh tomato slices improved after drying.

In comparison, the redness of the fresh tomatoes was significantly higher than the dried samples. The redness significantly decreased with air temperature from 27.96 to 19.63 in the range of 50 to $70^{\circ} \mathrm{C}$ but rose to 21.51 at $80^{\circ} \mathrm{C}$. This shows that, compared with the fresh tomatoes, there was red pigment degradation associated with hot air drying within the temperature range employed in this study. This pigment degradation was consistent with what Contreas et al. [20] reported for microwaveair drying of strawberry. The decrease in redness may be attributed to the occurrence of reaction between the amino acids and reducing sugars (Maillard reaction) in the tomato during drying. The yellowness of all dried tomato samples generally increased significantly $(\mathrm{p}=0.05)$ 
with increasing temperature indicating less browning. The yellowness increased from 22.68 in the fresh tomato to 37.19 for the samples dried at $80^{\circ} \mathrm{C}$. The values of the hue angles recorded for the dried samples ranged between $51.81^{\circ}$ and $61.95^{\circ}$, revealing that all the dried samples were yellow hued rather than red. This was consistent with published results by Al-Muhtaseb [38] for drying tomato pomace. The samples

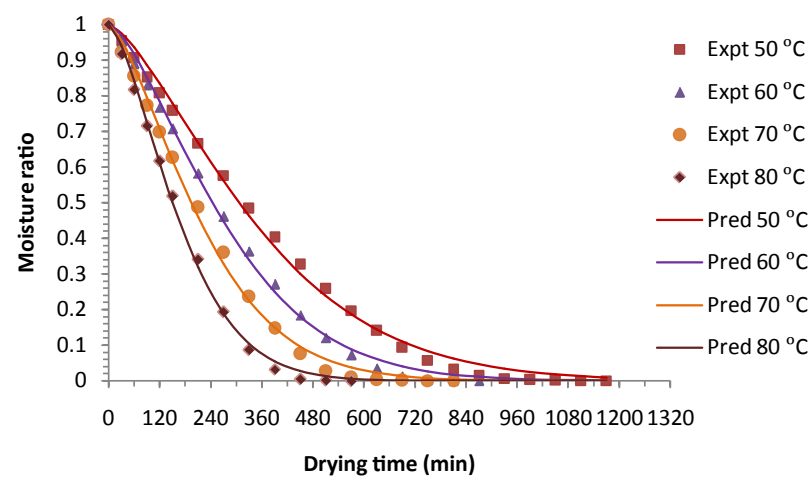

Figure 6: Fitting of hot-air drying of experimental and simulated data to the Page model.

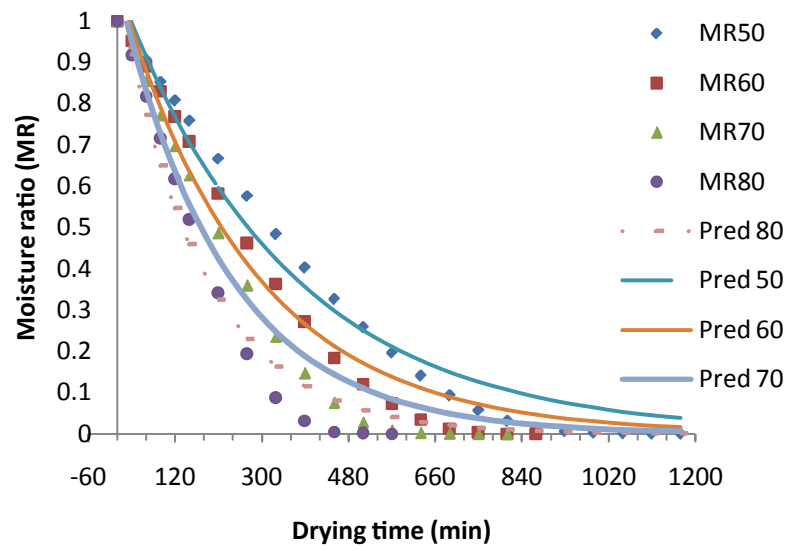

Figure 7: Fitting of hot-air drying of experimental and simulated data to the Henderson and Pabis model.

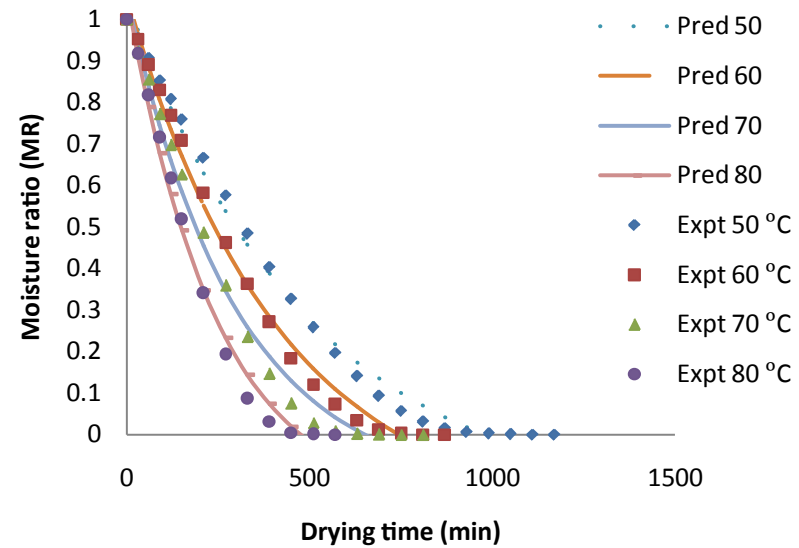

Figure 8: Fitting of hot-air drying of experimental and simulated data to the Logarithmic model.
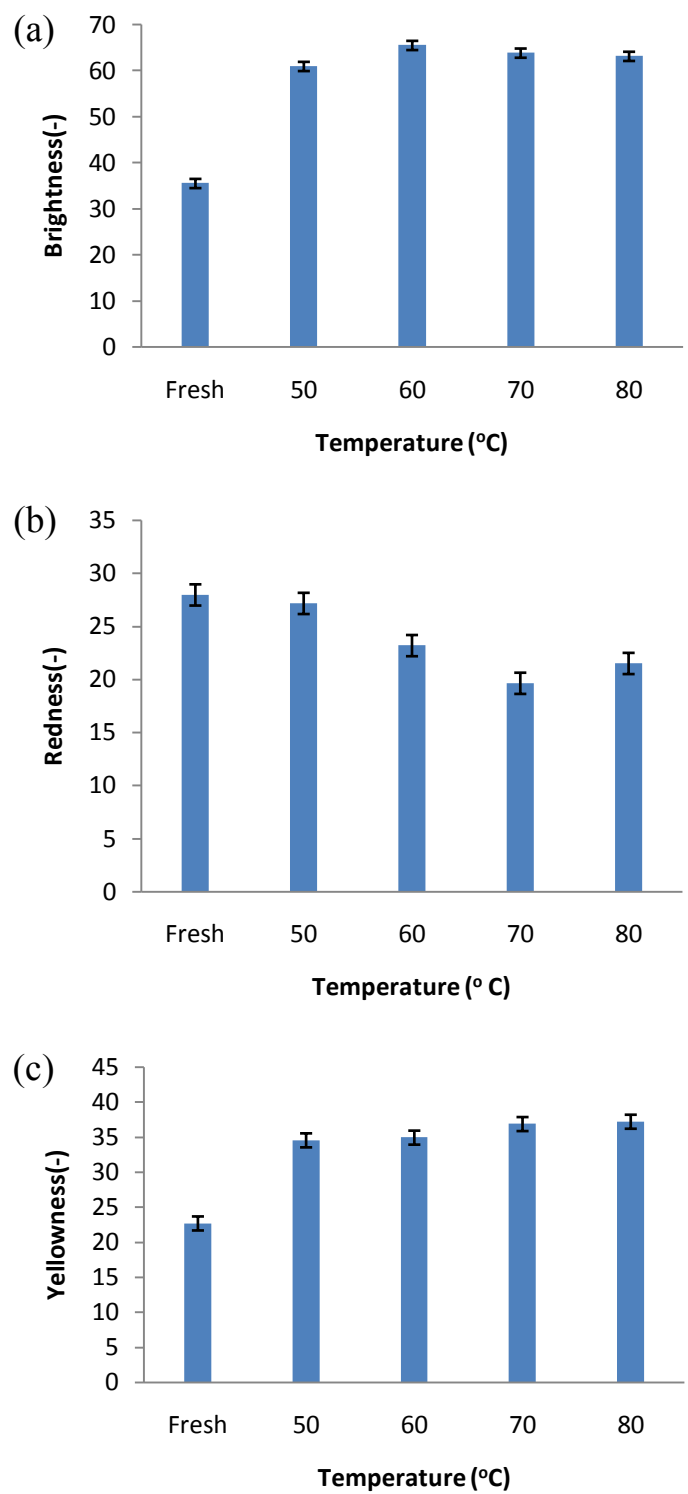

Figure 9: Variation of air temperature on the (a) brightness, (b) redness, and (c) yellowness of dried tomato slices compared with the fresh.

dried at $50^{\circ} \mathrm{C}$ were closer to the red hue of fresh tomatoes whereas the $70^{\circ} \mathrm{C}$ dried samples were closer to the yellow hue indicating that these samples are likely to be accepted best by consumers. The higher values of hue angles recorded by all dried samples compared with the fresh clearly indicate that less browning occurred. Hawlader et al. [39] reported that a decrease in hue angles $\left(\alpha^{\circ}\right)$ values is an indication of more brown pigment formation and shifting away from yellowness. In this study, there was rather an increase in hue angles, thus shifting it towards yellow. The higher $L$ values and $a / b$ values are desirable in dried products [40]. Nevertheless, higher L values in the dried samples may be related to anthocyanin degradation caused by microwaves on the surfaces of the samples [20].

\section{Influence of hot air temperature on non-enzymatic browning}

Browning is another quality criterion aside flavour and colour in the processing of tomatoes. The influence of hot air drying 
temperatures on the development of non-enzymatic browning in tomato is displayed in Figure 11. The extent of browning was evaluated spectrophotometrically as dried tomato extracts absorbance at $440 \mathrm{~nm}$. The results clearly show how BI increased with temperature from 0.051 in the fresh tomatoes to 1.40 after drying at $80^{\circ} \mathrm{C}$. This increasing BI with temperature indicates that the tomato slices were greatly affected by hot air temperature and the rate of brown pigment formation increased as drying rates increased during the drying process. The trend agrees with BI for conventional and multistage drying of tomato reported by Cernîşev [17]. The brown pigment formation in the dried tomatoes may be due to the reactions between nitrogenous constituents and reducing sugars, nitrogenous constituents and organic acids, and sugars and organic acids $[41,42]$.

\section{Influence of hot air temperature on lycopene content}

To compare the influence of hot air temperature on lycopene, the dried tomato slices lycopene content were compared with that of the fresh (Figure 12). The lycopene levels of the fresh tomatoes significantly $(\mathrm{p}=0.05)$ increased from $2.96 \mathrm{mg} / 100 \mathrm{~g}$ to $61.23,59.10,60.88$, and 65.28 $\mathrm{mg} / 100 \mathrm{~g}$ when air dried at $50,60,70$, and $80^{\circ} \mathrm{C}$ respectively. The values of the lycopene content obtained after hot air drying were relatively lower than the $82.90 \mathrm{mg} / 100 \mathrm{~g}$ reported by Takeoka et al [43] for tomato paste.

\section{Influence of hot air temperature on flavor}

Figure 13 displays the untransformed mean response signals from 12 tin dioxide sensors in the e-nose system for both the fresh and the dried samples. No consistent flavour degradation was recorded by all the twelve e-nose sensors. Eleven out of the twelve sensors used indicated flavour degradation of all dried samples compared with the

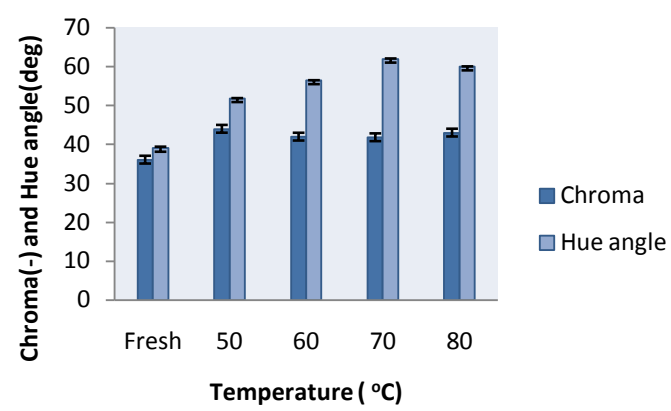

Figure 10: Influence of air temperature on the chroma and hue angle of fresh and dried tomatoes.

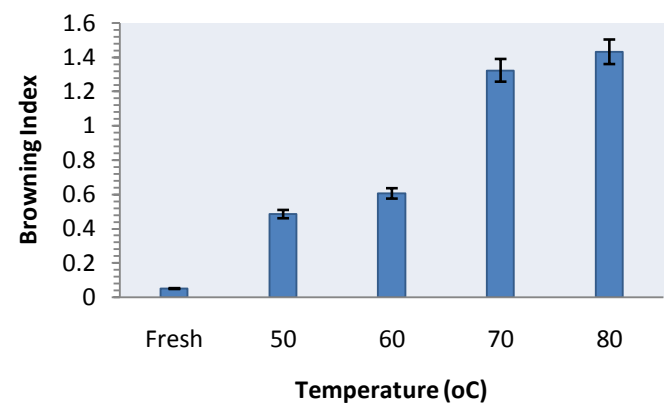

Figure 11: Dynamics of browning index against the fresh and dried samples at various hot air temperatures.

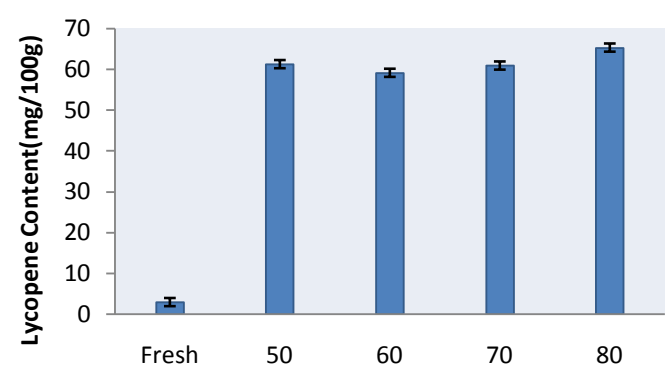

Temperature (oC)

Figure 12: Influence of hot air temperature on the lycopene content.

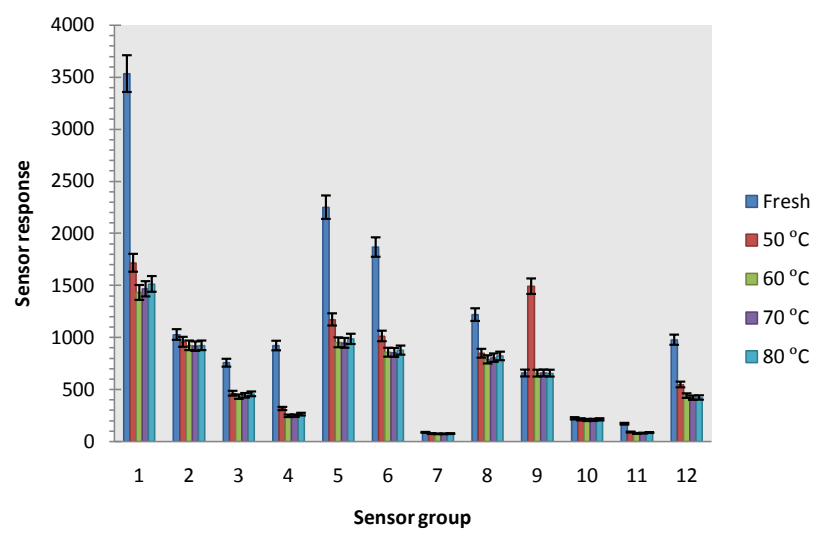

Figure 13: Untransformed mean flavour response signal by $12 \mathrm{SnO}_{2}$ sensors of fresh and dried tomato slices at various hot air temperatures.

fresh tomatoes. Two sensors showed no difference in flavour between all the dried samples but showed slight difference between the fresh and the dried tomatoes. These lower response signals by the e-nose for the dried samples might be due to the degradation of flavour compounds when exposed to the prolonged hot air temperatures. The result is similar to what was reported by Alibas et al. [19], Contreras et al. [20], Vadivambal and Jayas [18] for dried products.

\section{Conclusion}

It was shown that increase in hot air temperature enhanced the drying rate and significantly reduced the drying time of tomato slices. It was observed that the lycopene levels of the tomatoes increased significantly after drying whereas the flavour degraded. The increase in the hot air temperature increased the non-enzymatic browning. The brightness increased significantly with temperature from 50 to $60^{\circ} \mathrm{C}$ and then decreased from 70 to $80^{\circ} \mathrm{C}$ indicating that the luminance of the fresh tomatoes improved after drying. The redness of the samples dried at various temperatures decreased whilst the yellowness increased when compared with the fresh tomatoes while brown pigment formation increased with increasing temperature. The moisture diffusivity coefficient increased with increasing hot air temperature with Arrhenius type activation energy for moisture removal of 22.28 $\mathrm{kJ} / \mathrm{mol}$. Among the Page, Henderson and Pabis, and Logarithmic thinlayer drying models that were fitted to the experimental data, the Page model showed the best fit although the three models could satisfactorily describe the hot-air drying kinetics of tomato slices. 
Citation: Abano EE, Ma H, Qu W (2011) Influence of Air Temperature on the Drying Kinetics and Quality of Tomato Slices. J Food Process Technol 2:123. doi: $10.4172 / 2157-7110.1000123$

\section{References}

1. Celma AR, Cuadros F, López-Rodríguez, F (2009) Characterisation of industria tomato by-products from infrared drying process. J. Food and Bioproducts Processing 87: 282-291.

2. FAO (2010) Food and Agriculture Organization. FAO Water Development and Management Unit.

3. FAOSTAT (2010) FAO Statistics Database. Food and Agriculture Organization

4. Abano EE, Sam-Amoah LK (2011) Effects of different pretreatments on drying characteristics of banana slices. Journal of Engineering and Applied Science 6: article 3

5. Shi J, Yi C, Xue SJ, Jiang Y, Ma Y, et al. (2009) Effect of modifiers on the profile of lycopene extracted from tomato tomato skins by supercritical $\mathrm{CO}_{2} \mathrm{~J}$ Food Eng 93: 431-436.

6. Harvard School of Public Health (2010) Harvard University Press.

7. Toğrul H (2006) Suitable drying model for infrared drying of carrot. J food Eng 77: 610-619

8. Egydio JA, Moraes ÁM, Rosa PTV (2010) Supercritical fluid extraction of lycopene from tomato juice and characterization of its antioxidant activity. $J$ Supercritical Fluids 54: 159-164.

9. Di Mascio P, Kaiser S, Sies H (1989) Lycopene as the most efficient biological carotenoid singlet oxygen quencher. Arch. Biochem. Biophys 274: 532-538.

10. Levelly V, Torresani MC (2011) Modelling the stability of lycopene-rich byproducts of tomato processing. Food Chemistry 125: 529-535.

11. Vági E, Simándi B, Vásárhelyiné KP, Daood H, Kéry Á, et al (2007) Supercritica carbon dioxide extraction of caroteniods, tocopherols, and sitosterols from industrial tomato by-products. J. Supercritical Fluids 40: 218-226.

12. Cantuti-Castelvetri I, Shukitt-Hale B, Joseph JA (2000) Neurobehavioral aspects of antioxidants in aging. Int J Dev Neurosci 18: 367-381

13. Ferguson LR (1997) Micronutrients, dietry questionnaires and cancer. Biomed Pharcother 51: 337-344.

14. Yamaguchi M, Uchiyama S (2003) Effect of carotenoid on calcium content and alkaline phosphate activity in rat femoral tissues in vitro: the unique anabolic effect of beta-cryptoxanthin. Biol Pharm Bull 26: 1188-1191.

15. Rao AV, Agarwal S (2000) Role of antioxidant lycopene in cancer and heart diseases. J Am Coll Nutr 19: 563-569.

16. Arab L, Steck S (2000) Lycopene and cardiovascular disease. Am J Clin Nutr 71: 1691S-1695S.

17. Cernîşev S (2010) Effects of conventional and multistage drying processing on non-enzymatic browning in tomato. J Food Eng 96: 114-118

18. Vadivambal R, Jayson DS (2007) Changes in quality of microwave-treated agricultural products- a review. Biosystems Engineering 98: 1-16.

19. Alibas Ozkan I, Akbudak B, Akbudak N (2005) Microwave drying characteristics of spinach. J Food Eng 78: 577-583.

20. Contreras C, Martín-Esparza ME, Chiralt A, Martínez-Navarrete N (2008) Influence of microwave application on convective drying: Effect on drying kinetics, and optical mechanical properties of apple and strawberry. J Food Eng 88: 55-64

21. Maskan M (2001) Drying, shrinkage, and rehydration characteristics of kiwifruits during hot air and microwave drying. J Food Eng 48: 177-182.

22. Karaaslan SN, Tuncer IK (2008) Development of a drying model for combined microwave-fan-assisted convection drying of spinach. Biosystems Engineering 100: 44-52.

23. Doymaz I (2010) Drying of thyme (Thymus Vulgaris L.) and Selection of a suitable thin-layer drying model. J Food Processing and Preservation 35: 458-

24. Kose B, Erenturk S (2010) Drying Characteristics of mistletoe (Viscum album L.) in convective and UV combined convective type dryers. Industrial Crops and Products 32: 394-399.
25. Mota CL, Luciano C, Dias A, Barroca MJ, Gine RPF (2010) Convective drying of onion: Kinetics and nutrional evaluation. Food and Bioproducts Procesing 88: $115-123$

26. Akpinar EK (2006) Mathematical modeling of thin layer drying process unde open sun of some aromatic plants. Journal of Food Engineering 77: 864-870.

27. Erbay Z, Icier F (2010) Thin-layer drying behaviors of Olive leaves (Olea Europaea L.). Journal of Food Process Engineering 33: 287-308.

28. Doymaz I (2005) Drying characteristics and kinetics of okra. Journal of Food Engineering 69: 275-279

29. Vega A, Uribe E, Lemus R, Miranda M (2007) Hot air drying characteristics of aloe vera (Aloe barbadensis Miller) and influence of temperature on kinetic parameters. Lebensm-Wiss Technol 40: 1698-1707.

30. SPSS (2007) SPSS 16.0 for Windows SPSS Inc, Chicago, IL

31. Roberts JS, Kidd DR, Padilla-Zakour O (2008) Drying kinetics of grape seeds Journal of Food Engineering 89: 460-465

32. Singh U, Jain SK, Doshi A, Jain KH, Chahar KV (2008) Effects of Pretreatments on Drying Characteristics of Button Mushroom. International Journal of Food Engineering 4: art 5

33. Crank J (1975) The Mathematics of Diffusion. (2nd Edn), Clarendon Press, Oxford, UK.

34. Xiaobo Z, Jiewen Z (2008) Comparative analyses of apple aroma by a tin-oxide gas sensor array device and GC/MS. Food Chemistry 107: 120-128

35. Tikk K, Haugen JE, Andersen HJ, Aaslyng MD (2008) Monitoring of warmedover flavour in pork using the electronic nose- correlation to sensory attributes and secondary lipid oxidation products. Journal Meat Science 80: 1254-1263

36. Bai-Ngew S, Therdthai N, Dhamvithee P (2011) Characterization of microwave vacuum-dried durian chips. Food Engineering 104: 114-122

37. Figiel A (2009) Drying kinetics and quality of vacuum-microwave dehydrated garlic cloves and slices. Journal of Food Engineering 94: 98-104.

38. Al-Muhtaseb AH, Al-Harahsheh M, Hararah M, Magee TRA (2010) Drying characterisitics and quality change of unutilized-protein rich tomato pomace with and without osmotoic pre-treatment. J. Industrial Crops and Products 31 : 171-177

39. Hawlader MNA, Perera CO, Tian M, (2006) Properties of modified atmosphere heat pump dried foods. J. Food Eng 74: 392-401.

40. Arslan D, Özcan MM (2008) Evaluation of drying methods with respect to drying kinetics, mineral content, and colour characteristics of rosemary leaves. Energy Conversion and Management 49: 1258-1264

41. Zanoni B, Peri C, Nani R, Lavelli V, (1999) Oxidative heat damage of tomato halves as affected by drying. Food Research International 31: 395-401

42. Muratore G, Rizzo V, Licciardello F, Maccarone E (2008) Partial dehydration of cherry tomato at different temperature, and nutritional quality of the products Food Chemistry 111:887-891.

43. Takeoka GR, Dao L, Flessa S, Gillespie DM, Jewell WT, et al. (2001) Processing Effects on Lycopene Content and Antioxidant Activity of Tomatoes. J Agric Food Chem 49: 3713-3717

44. Akanbi CT, Adeyem RS, Ojo A (2006) Drying characteristics and sorption isotherm of tomato slices. J Food Eng 73: 157-163.

45. Bondaruk J, Markowski M, Blaszczak W (2007) Effect of drying conditions on the quality of vacuum-microwave dried potato cubes. J Food Eng 81: 306-312.

46. Ghodake HM, Goswami TK, Chakraverty A (2006) Mathematical modeling of withering characteristics of tea leaves. Dry Technol 24: 159-164.

47. Cui ZW, Sun LJ, Chen W, Sun DW (2008) Preparation of dry honey by microwave-vacuum drying. Journal of Food Engineering 84: 582-590.

48. Dadali, Gökçe, Apar, Kılıç D, Özbek et al. (2007) Estimatioin of Effective Moisture Diffusivity of Okra for Microwave Drying. Drying Technology 25: 1445 1450

49. Doymaz I (2007) Air-drying characteristics of tomatoes. J Food Eng 78: 1291 1297. 
Citation: Abano EE, Ma H, Qu W (2011) Influence of Air Temperature on the Drying Kinetics and Quality of Tomato Slices. J Food Process Technol 2:123. doi:10.4172/2157-7110.1000123

Page 9 of 9

50. Giri SK, Prasad S (2007) Drying kinetics and rehydration characteristics of microwave-vacuum and convective hot-air dried mushrooms. Journal of Food Engineering 78: 512-521.

51. Midilli A, Kucuk H, Yapar Z (2002) A new model for single layer drying. Dry Technol 20: 1503-1513.

52. Page GE (1949) Factors influencing the maximum rate of air drying shelled corn in thin layers. MS Thesis, Purdue University, West Lafayette, IN.

53. Magesh G, Regupathi I, Rose ML, Murugesan T (2010) Moisture diffusivty and energy consumption during microwave drying of plaster of Paris. Chemical product and Process Modeling 5: 1-23

54. Piotrowski D, Lenart A, Wardzynski A (2004) Influence of osmotic dehydration on microwave-convective drying of frozen strawberries. J Food Eng 65: 519525.

55. Prothon F, Ahrné L, Funebo T, Kidman S, Langton M, et al. (2000) Effects of combined osmotic and microwave dehydration of apple on texture, microstructure, and rehydration characteristics. LWT - Food Sci Technol 34 95-101.

56. Scaman CH, Durance TD (2005) Emerging Technologies for Food Processing. Elsevier Academic Press, London, 768.

57. Schiffmann R (2001) Microwave processes for the food industry. In: Datta A.

58. Sham PWY, Scaman CH, Durance TD (2001) Texture of vacuum microwave dehydrated apple variety. J Food Sci 66: 1341-1347.

59. Therdthai N, Zhou W (2009) Mathematical modeling of solar drying of apricot in thin layers. Journal of Food Engineering 91: 482-489.

60. Zhang J, Zhang M, Shan L, Fang Z (2007) Microwave-vacuum heating parameters for processing savory crisp bighead carp (Hypophthalmichthys nobilis) slices. J Food Eng 79: 885-891.

61. Zhang M, Tang J, Mujumdar A, Wang S (2006) Trends in microwave related drying of fruits and vegetables. Trends in Food Science and Technology 17: 524-534. 